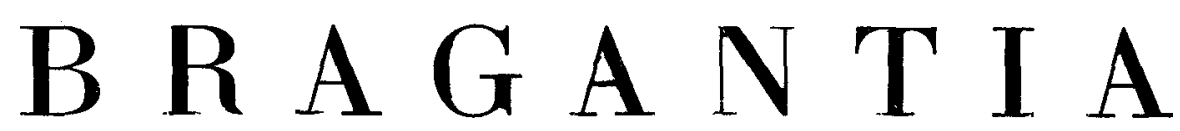

Boletim Científico do Instituto Agronômico do Estado de S. Paulo

Vol. 28

Campinas, junho de 1969

N. ${ }^{\circ} 18$

\title{
COMPORTAMENTO DE NOVAS VARIEDADES DE PIMENTÃO NA REGIÃO DE CAMPINAS $(1,2)$
}

José BotTER BeRnard, engenheiro-agrônomo, Seção de Olericultura, e Toshio IGUE, engenheiro-agrônomo, Seção de Técnica Experimental, Instituto Agronômico

\section{SINOPSE}

São apresentados os resultados de um ensaio de variedades de pimentão, em que, além da produtividade e qualidade do produto, verificou-se a resistência das variedades às viroses que atacam a cultura nas condições do Estado de São Paulo.

A variedade Agronômico-8 L 17 I-3944, superou enormemente as demais em produtividade e resistência às enfermidades.

Em segundo plano, quanto à produção, situaram-se as variedades: Moura I-3270, Pôrto Rico Wonder I-1799, Casca Grossa I-3187 e Yolo Wonder I-2095, que apresentam diferentes tipos de frutos.

As variedades menos produtivas foram: Amarelo I-2065, Mogi das Cruzes I-2199, World Beater I-486 e Yolo Wonder I-2095, que apresentaram sintomas mais severos das enfermidades.

\section{1 - INTRODUÇÃO}

O cultivo do pimentão (Capsicum annuum L.), hortaliça de alto valor nutritivo, no Estado de São Paulo, vem aumentando de ano para ano, tornando-se cultura econômica (1).

No presente trabalho são apresentados os resultados de um ensaio, instalado na Estação Experimental "Theodureto de Camargo", do Instituto Agronômico, em Campinas, no qual entraram em competição oito variedades dessa hortaliça. O experi-

(1) Trabalho apresentado na VIII Reuniăo Anual da Sociedade de Olericultura do Brasil, realizada em Curitiba, Estado do Paraná, de 14 a 20 de julho de 1968 Recebido para publicaçá em 23 de dezembro de 1968.

( $\left.{ }^{2}\right)$ A FAPESP colaborou na obtençáo dos dados experimentais e na produçáo de sementes genéticas, fornecendo uma camioneta para o transporte dos técnicos e de materiais. 
mento teve como principal objetivo, verificar quais as melhores variedades, sob os aspectos de produtividade e qualidade do produto. Visou também estudar a resistência das variedades às viroses, fator limitante da produção desta cultura em nossas condições.

\section{2 - MATERIAL E MÉTODOS}

As oito variedades estudadas, introduzidas na Seção de Olericultura, do Instituto Agronômico, são de diversas procedências, porém as sementes utilizadas neste ensaio foram produzidas nas estações experimentais do Instituto Agronômico, em Campinas e Monte Alegre do Sul.

Entraram em competição as seguintes variedades: Pôrto Rico Wonder I-1799, Mogi das Cruzes I-2199, Yolo Wonder I-2095, Casca Grossa I-3187, Moura I-3270, World Beater I-486, Amarelo I-2065 e Agronômico-8 L 17 I-3944.

O experimento foi conduzido em solo do tipo aluvial arenoso, com superposição de material arrastado de Latossolo Roxo, e de acidez fraca. A análise química do solo, efetuada pela Seção de Fertilidade do Solo, do Instituto Agronômico, revelou os seguintes resultados :

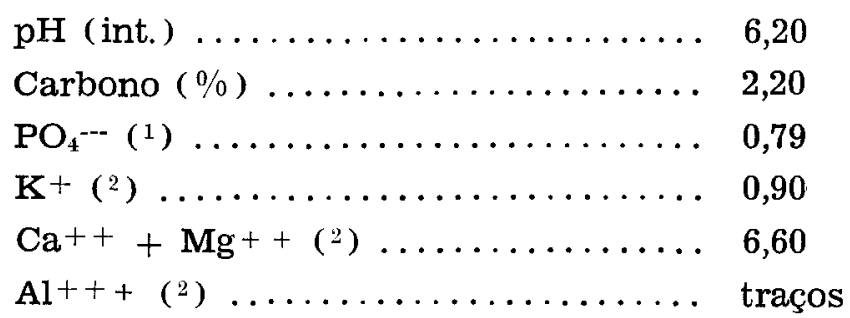

A adubação empregada por planta foi de $2 \mathrm{~kg}$ de composto, $250 \mathrm{~g}$ de superfosfato simples, $25 \mathrm{~g}$ de cloreto de potássio e $80 \mathrm{~g}$ de sulfato de amônio. Os três primeiros fertilizantes foram incorporados ao solo uma semana antes do transplante das mudas, e o adubo nitrogenado aplicado em cobertura, em quatro parcelas iguais, de $20 \mathrm{~g}$ cada, aos $20,35,50$ e 65 dias após aquela operação.

\footnotetext{
$\left(^{1}\right)$ e.mg/100 ml TFSA, solúvel em $\mathrm{H}_{2} \mathrm{SO}_{4} 0,05 \mathrm{~N}$.

(2) e.mg/100 ml TFSA, teores de trocáveis.
} 
A semeadura teve lugar no dia 12 de setembro, o transplante em 31 de outubro de 1967, e as colheitas, de 5 de janeiro a 14 de março de 1968. Nesse período as temperaturas médias mensais do ar foram respectivamente de $20,6^{\circ} \mathrm{C}-22,5^{\circ} \mathrm{C}-21,1^{\circ} \mathrm{C}-$ $20,7^{\circ} \mathrm{C}-22,1^{\circ} \mathrm{C}$ e $21,7^{\circ} \mathrm{C}$, para os meses de setembro, outubro, novembro e dezembro de 1967, e janeiro e fevereiro de $1968(2,3 \mathrm{e} 4)$. A temperatura mínima registrada foi de $11,0^{\circ} \mathrm{C}$, em setembro, e a máxima, de $33,7^{\circ} \mathrm{C}$ em outubro. A média das mínimas, para o período, foi de $17,1^{\circ} \mathrm{C}$, e a das máximas, de $27,9^{\circ} \mathrm{C}$.

Empregou-se o delineamento de blocos ao acaso, repetidos 5 vêzes, em canteiros de $3,20 \mathrm{~m}^{2}(1,60 \times 2,00 \mathrm{~m})$. O espaçamento adotado foi de $80 \times 40 \mathrm{~cm}$, de modo que cada canteiro constou de 2 linhas com 5 plantas cada, no total de 10 plantas por canteiro.

\section{3 - RESULTADOS E DISCUSSÃO}

No quadro 1 são apresentados os resultados das produções obtidas por metro quadrado, assim como o pêso médio de um fruto e a altura média das plantas, medidas estas tomadas por ocasião da primeira e da última colheita de cada variedade separadamente.

Os resultados da análise estatística das produções em pêso, considerando os frutos comerciáveis, revelaram o seguinte:

1 - Diferença altamente significativa entre as variedades.

2 - Comparando-se as médias das variedades pelo teste de Tukey, ao nivel de 5\% de probabilidade, verificou-se que a Agronômico-8 L 17 I-3944 foi superior às demais. Essa variedade, que apresenta frutos do tipo comercial, cônico-alongados, registrou a produção média de $4.070 \mathrm{~g}$ por $\mathrm{m}^{2}$. O pêso médio de um fruto foi de $60 \mathrm{~g}$.

3 - Entre variedades Moura I-3270, Pôrto Rico Wonder I-1799, Casca Grossa I-3187 e Yolo Wonder I-2095 não houve diferenças significativas. As produções médias por $\mathrm{m}^{2}$ variaram de $2.630 \mathrm{~g}$, para a Moura, a $1.750 \mathrm{~g}$ para a Yolo Wonder. O pêso médio de um fruto oscílou entre $49 \mathrm{~g}$ e $51 \mathrm{~g}$. 
QUAdRo 1. - Produção de frutos comerciáveis de pimentão por metro quadrado, pêso médio dos frutos e altura média das plantas, obtidos em ensaio de variedades conduzido em Campinas

\begin{tabular}{|c|c|c|c|c|c|}
\hline \multirow{3}{*}{ Variedade } & \multirow{2}{*}{\multicolumn{2}{|c|}{$\begin{array}{c}\text { Produção por metro } \\
\text { quadradio }\end{array}$}} & \multirow{3}{*}{$\begin{array}{l}\text { Pêso } \\
\text { médio dos } \\
\text { frutos }\end{array}$} & \multicolumn{2}{|c|}{ Altura das plantas } \\
\hline & & & & 66 dias & 135 dias \\
\hline & $\begin{array}{c}\text { Número } \\
\text { de frutos }\end{array}$ & Pêso & & \multicolumn{2}{|c|}{ após o transplante } \\
\hline & & kg & $\mathrm{g}$ & $\mathbf{c m}$ & $\mathbf{c m}$ \\
\hline Agronômico-8 L 17 I-3944 $\ldots$ & 68 & 4,07 & 60 & 52 & 81 \\
\hline Moura I-3270 $\ldots \ldots$ & 54 & 2,63 & 49 & 40 & 55 \\
\hline Pôrto Rico Wonder I-1799 ... & 50 & 2,53 & 50 & 40 & 58 \\
\hline Casca Grossa I-3187 .... & 41 & 2,02 & 50 & 42 & 67 \\
\hline Yolo Wonder I-2095 & 34 & 1,75 & 51 & 34 & 45 \\
\hline World Beater I $-486 \ldots \ldots \ldots$ & 39 & 1,55 & 40 & 35 & 55 \\
\hline Mogi das Cruzes I-2199 & 29 & 1,36 & 46 & 38 & 57 \\
\hline Amarelo I-2065 $\ldots \ldots \ldots \ldots$ & 23 & 0,99 & 43 & 36 & 41 \\
\hline
\end{tabular}

4 - A variedade Moura I-3270 mostrou-se significativamente superior à World Beater I-486, Mogi das Cruzes I-2199 e Amarelo I-2065, cujas produções médias por $\mathrm{m}^{2}$ foram inferiores a $1.550 \mathrm{~g}$.

5 - Entre as variedades Yolo Wonder I-2095, World Beater I-486, Mogi das Cruzes I-2199 e Amarelo I-2065 não houve diferenças significativas. A Amarelo, que se apresenta com os frutos amarelo-alaranjados, quando maduros, foi a variedade menos produtiva, com $990 \mathrm{~g}$ por $\mathrm{m}^{2}$. O pêso médio de um fruto foi de $43 \mathrm{~g}$.

6 - O coeficiente de variação foi de $22,6 \%$. 


\section{$4-$ CONCLUSÕES}

Nas condições do presente ensaio, evidenciou-se que a variedade Agronômico-8 L 17 I-3944 de pimentão superou enormemente tôdas as demais, em produção, tamanho dos frutos, desenvolvimento das plantas e resistência às enfermidades. Seus frutos, cônico-alongados, são do tipo comercial (5).

Em segundo plano, quanto à produção, situaram-se as variedades Moura I-3270, Pôrto Rico Wonder I-1799, Casca Grossa I-3187 e Yolo Wonder I-2095, apresentando diferentes tipos de frutos. Os frutos da variedade Casca Grossa, alongados, com polpa espêssa, resistentes e de belo aspecto, se destacam dos demais e pertencem ao tipo atualmente preferido pelo consumidor paulista.

As variedades menos produtivas foram: Amarelo I-2065, Mogi das Cruzes I-2199, World Beater I-486 e Yolo Wonder I-2095, que apresentaram sintomas mais severos de viroses.

BEHAVIOR OF NEW VARIETIES OF SWEET PEPPER IN THE AREA OF CAMPINAS

\section{SUMMLARY}

In this paper results of a trial of sweet pepper varieties are presented.

The authors had in mind to study, besides productivity and quality, the resistance of the varieties to virus diseases, a factor which behinders and limits production of this crop under our conditions.

Variety Agronômico-8 L 17, created in the Seção de Virologia of the instituto Agronomico, and which produces fruits of conical-elongated shape, for the trade, outdid by far the others in productivity and in resistance to diseases.

The following varieties reached the second place in productivity: Moura, Porto Rico Wonder, Casca Grossa and Yolo Wonder, producing different types of fruits.

Less productive were the varieties Amarelo, Mogi das Cruzes, World Beater and Yolo Wonder, which presented more severe symptoms of ciseases. 


\section{LITERATURA CITADA}

1. BERNARDI, J. B. Instruções para a cultura do pimentão. Campinas, Instituto Agronômico, 1968. 17fls. (Nã̃o publicado)

2 CAMPINAS. Instituto Agronômico. Resumo dos dados meteorológico de Campinas - Setembro de 1967. Agronômico 19(9/10):48, 1967.

3. Resumo dos dados meteorológicos de Campinas Outubro e Novembro de 1967 . Agronômico $19(11 / 12): 43,48,1967$.

4. - Resumo dos dados meteorológicos de Campinas -.. Dezembro de 1967 e Janeiro e Fevereiro de 1968. In: Relatórios da Seção de Climatologia, do Instituto Agronômico, 1967 e 1968. (Não publicados)

5. NAGAI, H. Obtenção de variedades de pimentão resistentes mosaico. Piracicaba, Escola Superior de Agricultura "Luiz de Queircz", 1967. 59fls. + 2 pranchas. (Tese) 